\title{
In vitro Interactions of Secnidazole and Its Iron (II), Copper (II) Complexes with Bovine Serum Albumin by Fluorescence Quenching Method
}

\author{
Md. Jamal Hossain ${ }^{1}$, Md. Zakir Sultan², Mohammad A. Rashid ${ }^{1}$ \\ and Md. Ruhul Kuddus ${ }^{1}$ \\ ${ }^{1}$ Department of Pharmaceutical Chemistry, Faculty of Pharmacy, University of Dhaka \\ Dhaka-1000, Bangladesh \\ ${ }^{2}$ Centre for Advanced Research in Sciences, University of Dhaka, Dhaka-1000, Bangladesh
}

(Received: December 02, 2019; Accepted: January 28, 2020; Published: January 30, 2020)

\begin{abstract}
The current study was designed to investigate the interactions of an antimicrobial drug secnidazole and its two transition metal complexes with bovine serum albumin (BSA). The interactions of secnidazole and its both transition metal complexes were confirmed by the extingushing of fluorescence intensity of the protein. The fluorescence quenching of BSA by the drug and its both metal complexes showed a static quenching process and the reactions followed exothermic mechanism. The fluorescence spectroscopic method was utilized to evaluate the thermodynamic parameters like change of enthalpy $(\Delta \mathrm{H})$, entropy $(\Delta \mathrm{S})$ and Gibb's free energy $(\Delta \mathrm{G})$ which indicated the bindings of the antimicrobial agent and its both metal chelates were hydrogen bonding and van der Waals interactions. The binding constant and the number of binding sites were also measured by double log plot that indicated the drug or its metal complexes bound with BSA at 1:1 ratio.
\end{abstract}

Key words: Secnidazole, metal complex, fluorescence quenching, Stern-Volmer constant, Van't Hoff plot

\section{Introduction}

Secnidazole (1-(2-hydroxypropyl)-2-methyl-5nitroimidazole), a 5-nitroimidazole derivative is used as an antimicrobial drug. Secnidazole shows potent antimicrobial activity against susceptible pathogens through the mechanism of diffusion into the bacterial cell. The inactive parent pro-drug compound became the active cytotoxic metabolite which leads to cellular damage, and finally, cell death (Oliveira et al., 2019).

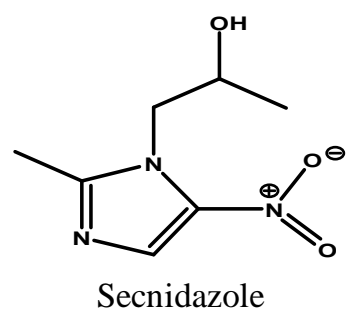

Serum albumins (SAs) are the most soluble and plentiful protein present in cardiovascular system, accounts for $50 \%$ to $65 \%$ of the plasma levels of total protein and involve in the binding and transportation of various biomolecules and drugs (Wang et al., 2016; Cheng et al., 2013). As most of the medications reversibly bind to serum albumins, they are commonly transported in the circulatory system as protein complexes. Therefore, drug-protein interaction has a vast biological interest which can play an important role in the study of drug stability and toxicity during chemotherapeutic process (Shahabadi and Hadidi, 2014; Sun et al., 2006). This sort of drug-protein interaction can also affect the drug stability and toxicity amid chemotherapeutic process. Since the existence of interaction between drug particles and proteins can give helpful data

Correspondence to: Md. Ruhul Kuddus; Email: ruhulkuddus@du.ac.bd

DOI: https://doi.org/10.3329/bpj.v23i1.45313 
about the structural characteristics or basic highlights of small molecules and provide new opportunities for the advancement of new drugs, hence studying the interaction of the new drug with protein is important (Reshma et al., 2019). Bovine serum albumin (BSA) is widely used as an in vitro model for studying drugprotein interaction, since its composition is $76 \%$ similar to that of human serum albumin (Ran et al., 2007; Khan et al., 2016).

The principal goal of this study was to investigate the nature of the bindings of free secnidazole and its iron (II), copper (II) complexes with BSA by fluorescence quenching method at physiological $\mathrm{pH}$ 7.4. By calculating the SternVolmer constant, the binding constant and the binding points at different temperatures $(298 \mathrm{~K}, 308$ $\mathrm{K}$ and $318 \mathrm{~K}$ ) at physiological $\mathrm{pH} 7.4$, the detection and characterization of the bindings of these metal chelates and the pure secnidazole with BSA were investigated. In addition, different thermodynamic factors such as change of enthalpy $(\Delta \mathrm{H})$, entropy $(\Delta \mathrm{S})$ and free energy $(\Delta \mathrm{G})$ were determined to analyze the nature of the binding strengths.

\section{Materials and Methods}

Apparatus. In this study a fluorescence spectrophotometer, F-7000 (Hitachi, Japan) equipped with $1.0 \mathrm{~cm}$ quartz cell, a thermostatic water bath (Unitronic Orbital, P Spectra, Spain), an analytical balance (AS 220.R2 Shimadzu, Japan), a sonicator (UltrasonsMedi II), pH meter (Orion Star A111) were also used for the analysis.

Drugs and chemicals. Standard secnidazole was gift from ACI Pharmaceuticals Ltd., Dhaka, Bangladesh. Potassium dihydrogen orthophosphate, potassium phosphate dibasic and BSA were of analytical grade and purchased from the local market. The BSA solution was prepared in phosphate buffer ( $\mathrm{pH}$ 7.4). All metal salts were collected from department of Pharmaceutical Chemistry, university of Dhaka, Bangladesh.
Preparations of buffer solution (Saha et al., 2013)

pH 7.4. About $65 \mathrm{ml}$ of $0.01 \mathrm{M} \mathrm{KH}_{2} \mathrm{PO}_{4}$ was mixed with $235 \mathrm{ml}$ of $0.01 \mathrm{M} \mathrm{K}_{2} \mathrm{HPO}_{4}$ and diluted to $1000 \mathrm{ml}$ with DM water.

\section{Preparations of stock solutions (Saha et al., 2013)}

Secnidazole. To prepare $100 \mathrm{ml}$ buffer solution $\left(1 \times 10^{-2} \mathrm{M}\right), 185.18 \mathrm{mg}$ of secnidazole was dissolved in demineralized water $\&$ the volume was adjusted up to $100 \mathrm{ml}$ with the same solvent and finally kept in a sonicator for $10 \mathrm{~min}$ at room temperature for proper dissolution. The stock solution was diluted to the desired strength by buffer solutions.

Preparation of metal solutions (Refat et al., 2013)

Ferrous sulfate solution. $100 \mathrm{ml}$ stock solution of $1 \times 10^{-2} \mathrm{M}$ was prepared by dissolving $278.02 \mathrm{mg}$ of ferrous sulfate heptahydrate, $\mathrm{FeSO}_{4} \cdot 7 \mathrm{H}_{2} \mathrm{O}$, in demineralized water to dissolve it \& finally the volume was adjusted up to $100 \mathrm{ml}$ with the same solvent.

Copper sulfate solution. $100 \mathrm{ml}$ stock solution of $1 \times 10^{-2} \mathrm{M}$ was prepared by dissolving $249.6 \mathrm{mg}$ of copper sulfate pentahydrate, $\mathrm{CuSO}_{4} .5 \mathrm{H}_{2} \mathrm{O}$, in demineralized water \& finally the volume was adjusted up to $100 \mathrm{ml}$ with the same solvent. Finally both ferrous sulfate solution and copper sulfate solution were kept in a sonicator for $10 \mathrm{~min}$ at room temperature for proper dissolution.

\section{Measurement of fluorescence quenching}

Fluorescence emissions are extremely susceptible to the local environment, and therefore the fluorophore transfer from high to low polarity environments usually leads spectral shifts (10-20 $\mathrm{nm}$ ) of the drugs in the excitation and emission spectra (Aleksić and Kapetanović, 2014).

The fluorescence spectra were recorded at 298K, $308 \mathrm{~K}$ and $318 \mathrm{~K}$ temperatures and a circulating water bath was used to maintain the temperatures. The concentrations of BSA were stabilized at $10 \mathrm{uM}$ and it was $20 \mathrm{uM}$ (during secnidazole-copper (II)-protein complex) and the concentrations of aqueous drug secnidazole and its metal complexes were varied from 5 to $100 \mu \mathrm{M}$. Most fluorescence emission spectra in the range of $200-500 \mathrm{~nm}$ were reported at a 
wavelength of $280 \mathrm{~nm}$ for excitation. The test tubes containing the solution of BSA and drug or its metal chelate were hatched at least $10 \mathrm{~min}$ before the measurements were taken (Tanwir et al., 2012).

The protein, mainly originated from tryptophen (Trp), tyrosin (Tyr) and phenylalanine (Phe), is considered to have intrinsic fluorescence. When other molecules like drugs or their metal complexes interact with protein, its intrinsic fluorescence often changes with ligands concentrations (Suryawanshi et al., 2016). Extinguishing of fluorescence strength of a fluorophore due to molecular interactions with other molecules is called fluorescence quenching which can be classified as dynamic or static process (Amin et al., 2016). If the quenching constant is augmented with increasing temperature is known as dynamic quenching whereas in the static quenching it is deducted with the increasing temperature. In energetic extinguishing process, the fluorophore and the quencher come into contact amid the life time excited state, in contrast, inactive extinguishing process alludes to fluorophore quencher complex formation (Joly et al., 2016; Ran et al., 2007). To study the interaction, the fluorescence quenching data can be depicted by the Stern-Volmer (SV) equation (Tang et al., 2015):

$$
\mathrm{F}_{0} / \mathrm{F}=1+\mathrm{K}_{\mathrm{q}} \tau_{0}[\mathrm{Q}]=1+\mathrm{K}_{\mathrm{SV}}[\mathrm{Q}]
$$

Where $F_{0}$ is fluorescence intensity before the quencher is applied, $\mathrm{F}$ is fluorescence intensity after the quencher is added. $\mathrm{Kq}$ is the bimolecular quenching rate constant with units of $\mathrm{L} \mathrm{mol}^{-1} \mathrm{~s}^{-1} \cdot \tau_{0}$ is the average life time $\left(\tau_{0}=10^{-8} \mathrm{~s}\right)$ of the serum albumin without any quencher.[Q] is the dissociated quencher concentration with units of molL ${ }^{-1}$. Hence, Stern-Volmer (SV) equation can be utilized to calculate Ksv by linear regression of a plot of $F_{0} / F$ against $[Q]$. To determine the minimum energy required for the interaction, known as activation energy, the following Arrhenius equation can be utlized (Qiong et al., 2009):

$$
\ln \mathrm{Kq}=-\left(\mathrm{E}_{\mathrm{a}} / \mathrm{RT}\right)+\ln \mathrm{A}
$$

Where, $\mathrm{Kq}$ is the quenching rate constant at the corresponding temperature, $\mathrm{Ea}$ is the activation energy of the extinguishing process, $R$ is the gas constant, $\mathrm{T}$ is the absolute temperature, where $\mathrm{A}$ is the pre-exponential factor.

\section{Thermodynamic parameters and nature of the binding forces}

Thermodynamic process is regarded responsible for the complex formation and temperature dependent thermodynamic parameters are calculated for further investigation of the acting forces between drugs and protein (Abdelhameed, 2015). The binding forces between quencher and proteins may be classified as hydrophobic force, electrostatic interactions, Van der Waals interactions and hydrogen bonds (Tang et al., 2015). The thermodynamic parameters, which values are considered as principle requirements for deciding the nature of interaction forces, can be calculated using the following van't Hoff equation (Sultana et al., 2013):

$$
\ln \mathrm{Ka}=-(\Delta \mathrm{H} / \mathrm{RT})+(\Delta \mathrm{S} / \mathrm{R})
$$

Where, $\Delta \mathrm{S}=$ entropy change is, $\mathrm{Ka}=$ constant at the corresponding temperature analogous to the Stern-Volmer quenching constants $\mathrm{K}_{\mathrm{SV}}, \mathrm{R}=$ the gas constant. Based on the slope and intercept of the fitted curve of $\ln \mathrm{K}_{\mathrm{SV}}$ against $1 / \mathrm{T}$, both $\Delta \mathrm{H}$ and $\Delta \mathrm{S}$ were calculated. It is possible to estimate the change of free energy $(\Delta \mathrm{G})$ from the following relationship:

$$
\Delta \mathrm{G}=\Delta \mathrm{H}-\mathrm{T} \Delta \mathrm{S}
$$

The negative sign for $\Delta \mathrm{G}$ demonstrates that the interaction process is spontaneous. When $\Delta \mathrm{H}>0$, $\Delta \mathrm{S}>0$, hydrophobic interaction occurs, when $\Delta \mathrm{H}<0$, $\Delta \mathrm{S}<0$, van der Waals forces and hydrogen bonds are responsible for the interactions, when $\Delta \mathrm{H}<0, \Delta \mathrm{S}>0$, only electrostatic forces are responsible for the quenching process (Ang et al., 2006).

\section{Binding constant and binding points}

By the following equation, the binding constant and the number of binding sites can be determined (Cheng et al., 2013):

$$
\log \left\{\left(\mathrm{F}_{0}-\mathrm{F}\right) / \mathrm{F}\right\}=\log \mathrm{K}_{\mathrm{b}}+\mathrm{nlog}[\mathrm{Q}]
$$

Where, respectively, $\mathrm{K}_{\mathrm{b}}$ and $\mathrm{n}$ describe the constant of binding to a site and the number of binding per 
molecule. It is possible to calculate the values of $\mathrm{K}_{\mathrm{b}}$ and $\mathrm{n}$ from the intercept and slope values of the $\log$ $\left\{\left(\mathrm{F}_{0}-\mathrm{F}\right) / \mathrm{F}\right\}$ vs. $\log [\mathrm{Q}]$ plot.

\section{Data analysis}

Microsoft Excel (MS Excel, 2010) was used to analyze the data and all the chemical structures were drawn by using ChemDraw ultra 7.0.

\section{Results and Discussion}

BSA fluorescence quenching spectra with different concentrations of secnidazole and its two metal complexes $(2: 1)$ were measured under physiological conditions as shown in Figure 1(a-i). It was clearly viewed that the presence of drug individually or its complexes with metal leads to a decrease in fluorescence intensity in the maximum emission wavelength. The Stern-Volmer plots for quenching BSA fluorescence by secnidazole and its 2:1 metal complexes at different temperatures were showed in figure 2 (a-c) and the corresponding SternVolmer quenching constants Ksv and quenching rate constants $\mathrm{kq}$ were listed in table 1 . These results indicated that the pure API or its metal chelates were likely to quench BSA fluorescence as a dynamic quenching mechanism because Ksv values augmented with rising temperature. From the Arrhenius plot (Figure 3) the activation energy of the quenching mechanism was calculated and the found values were stated in table 1 .

\section{Analysis of thermodynamic parameters and nature of the binding forces}

The thermodynamic parameters were determined from linear van't Hoff Plot (Figure 4, Table 2) based on the binding constants at the three different temperatures, $298 \mathrm{~K}, 308 \mathrm{~K}$ and $318 \mathrm{~K}$. The negative sign for $\Delta \mathrm{G}$ confirmed that the process of interaction was spontaneous. The negative $\Delta \mathrm{H}$ and $\Delta \mathrm{S}$ values suggested that the bindings of secnidazole and its iron (II), copper (II) complexes with BSA were mainly enthalpy-driven, with little contribution from the entropy factor where hydrogen bonding and van der Waals interactions performed vital role in the reactions (Qiong et al., 2009). These bindings were exothermic reactions due to negative change of enthalpy that was associated with the temperature increase in $\mathrm{K}$ values (Suryawanshi et al.,2016).

\section{Analysis of binding equilibria: Binding constant and binding points}

The binding constants $\left(\mathrm{K}_{\mathrm{b}}\right)$ and the number of binding sites (n) were calculated from the plot of $\log (\mathrm{Fo}-\mathrm{F}) / \mathrm{F}$ vs $\log [\mathrm{Q}]$, Figure $5(\mathrm{a}-\mathrm{c})$ and these values were listed in the table 6.Table 6 demonstrated that

Table 1. Stern-Volmer quenching constants of the secnidazole-BSA, secnidazole-Fe-BSA and secnidazole-Cu-BSA system at different temperatures at physiological pH 7.4.

\begin{tabular}{|c|c|c|c|c|c|c|c|c|}
\hline System & $\begin{array}{c}\mathrm{T} \\
(\mathrm{K})\end{array}$ & $\begin{array}{c}1 / \mathrm{T} \\
\left(\mathrm{K}^{-1}\right)\end{array}$ & $\mathrm{R}^{2}$ & $\begin{array}{c}\text { Ksv } \\
\left(\text { L.mole }^{-1}\right)\end{array}$ & $\operatorname{lnKsv}$ & $\begin{array}{c}\mathrm{K}_{\mathrm{q}}\left(\times 10^{12}\right. \\
\left.\text { L.mole }{ }^{-1} \cdot \mathrm{s}^{-1}\right)\end{array}$ & $\operatorname{lnKq}$ & $\begin{array}{l}\mathrm{Ea}(\mathrm{KJ} . \\
\left.\mathrm{mole}^{-1}\right)\end{array}$ \\
\hline \multirow[t]{3}{*}{ SD - BSA } & 298 & 0.0033 & 0.935 & 9000 & 9.1 & 0.90 & 27.52 & -336.56 \\
\hline & 308 & 0.0032 & 0.8675 & 5500 & 8.61 & 0.55 & 27.03 & -336.56 \\
\hline & 318 & 0.0031 & 0.7776 & 4000 & 8.29 & 0.40 & 26.71 & -336.56 \\
\hline \multirow{3}{*}{$\begin{array}{c}\text { SD-Fe- } \\
\text { BSA }\end{array}$} & 298 & 0.0033 & 0.9471 & 14600 & 9.58 & 1.46 & 28.00 & -444.60 \\
\hline & 308 & 0.0032 & 0.7740 & 4100 & 8.31 & 0.41 & 26.73 & -444.60 \\
\hline & 318 & 0.0031 & 0.9896 & 5000 & 8.51 & 0.50 & 26.93 & -444.60 \\
\hline \multirow{3}{*}{$\begin{array}{c}\text { SD-Cu- } \\
\text { BSA }\end{array}$} & 298 & 0.0033 & 0.9854 & 34800 & 10.45 & 3.48 & 28.87 & -203.60 \\
\hline & 308 & 0.0032 & 0.9810 & 29100 & 10.27 & 2.91 & 28.70 & -203.60 \\
\hline & 318 & 0.0031 & 0.9665 & 21200 & 9.96 & 2.12 & 28.38 & -203.60 \\
\hline
\end{tabular}

Here, $\mathrm{SD}=$ Secnidazole 


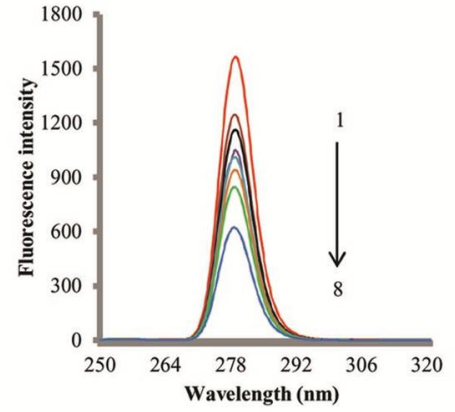

(a)

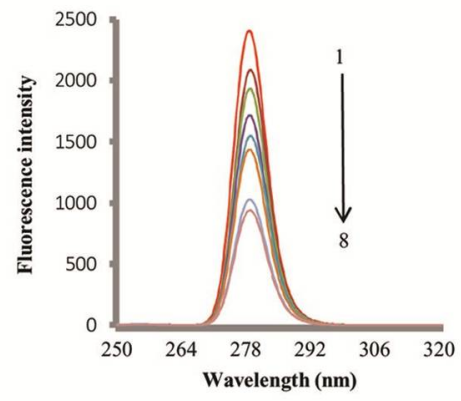

(d)

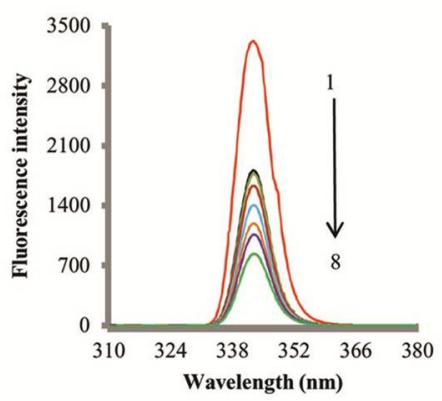

(g)

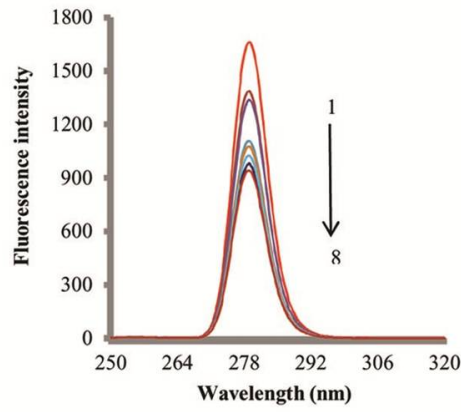

(b)

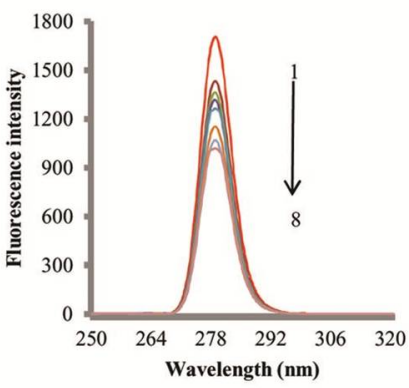

(e)

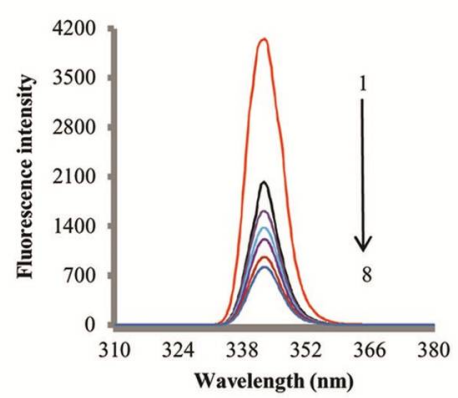

(h)

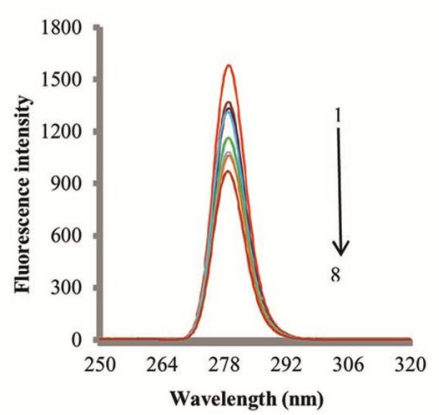

(c)

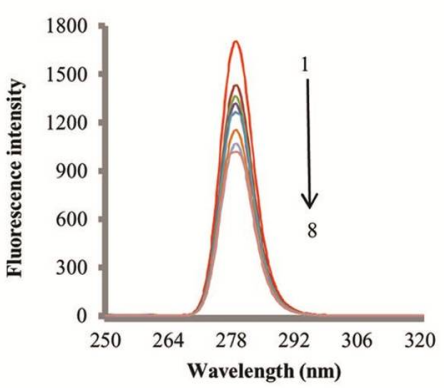

(f)

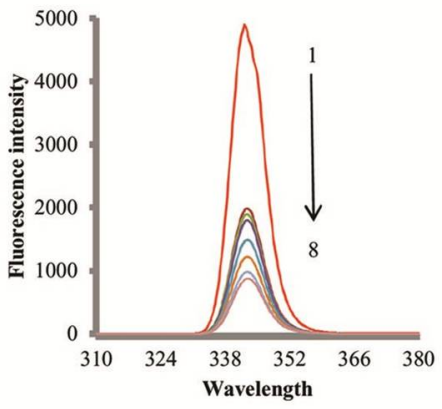

(i)

Figure 1. Fluorescence spectra of BSA in the presence of various concentrations of secnidazole at (a) $298 \mathrm{~K}$ (b) $308 \mathrm{~K} \&$ (c) $318 \mathrm{~K}$, its iron (II) complex at (d) $298 \mathrm{~K}$, (e) $308 \mathrm{~K} \&$ (f) $318 \mathrm{~K}$ and its copper (II) complex at (g) $298 \mathrm{~K}$, (h) $308 \mathrm{~K} \&$ (i) $318 \mathrm{~K}$. $\left(\lambda_{\mathrm{ex}}=280 \mathrm{~nm}\right) . C(\mathrm{BSA})=10 \times 10^{-6} \mathrm{~mol} \cdot \mathrm{L}^{-1}$ and it was $20 \times 10^{-6} \mathrm{~mol} \cdot \mathrm{L}^{-1}$ during copper (II) complex. Curves $1-8$ : $0,5,10,20,40,60,80 \& 100 \mathrm{uM}$ drugs or its metal complex respectively.

Table 2. Thermodynamic parameters of secnidazole-BSA, secnidazole-Fe-BSA and secnidazole-Cu-BSA system at different temperatures.

\begin{tabular}{cccccc}
\hline System & $\mathrm{T}(\mathrm{K})$ & $1 / \mathrm{T}\left(\mathrm{K}^{-1}\right)$ & $\Delta \mathrm{H}(\mathrm{KJ} / \mathrm{mol})$ & $\Delta \mathrm{S}(\mathrm{J} / \mathrm{mol} / \mathrm{K})$ & $\Delta \mathrm{G}(\mathrm{KJ} / \mathrm{mol})$ \\
\hline \multirow{3}{*}{ SD - BSA } & 298 & 0.0033 & -336.56 & -35.68 & -325.92 \\
& 308 & 0.0032 & -336.56 & -35.68 & -325.57 \\
& 318 & 0.0031 & -336.56 & -35.68 & -325.21 \\
\hline \multirow{3}{*}{ SD-Fe-BSA } & 298 & 0.0033 & -444.59 & -69.13 & -423.98 \\
& 308 & 0.0032 & -444.59 & -69.13 & -423.29 \\
\hline \multirow{3}{*}{ SD-Cu-BSA } & 318 & 0.0031 & -444.59 & -69.13 & -422.60 \\
& 298 & 0.0033 & -203.59 & 19.78 & -209.48 \\
& 308 & 0.0032 & -203.59 & 19.78 & -209.68 \\
\hline
\end{tabular}




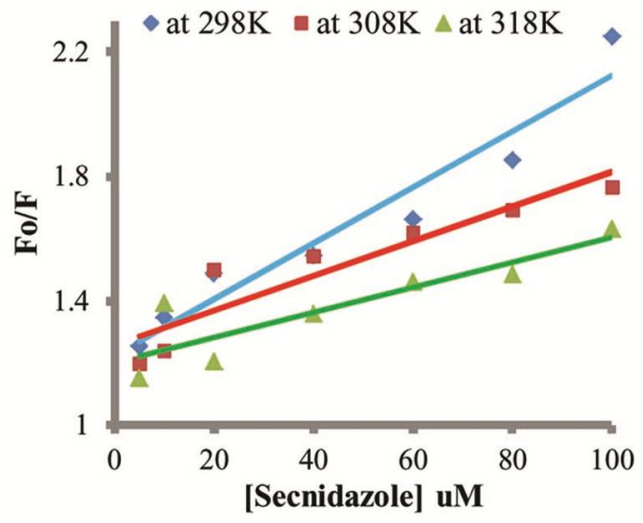

(a)

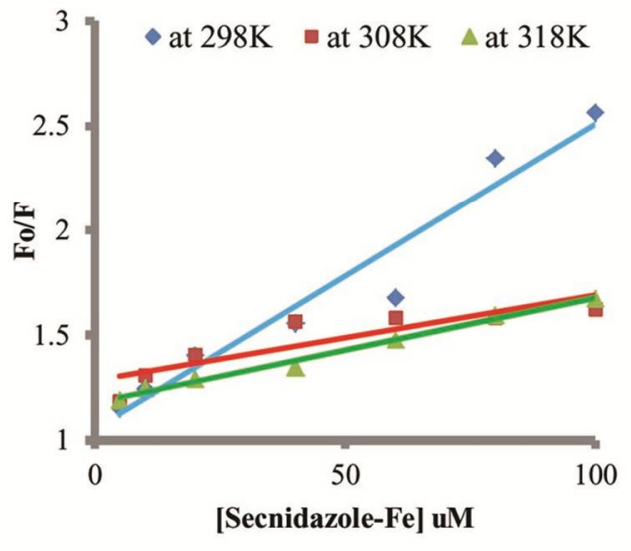

(b)

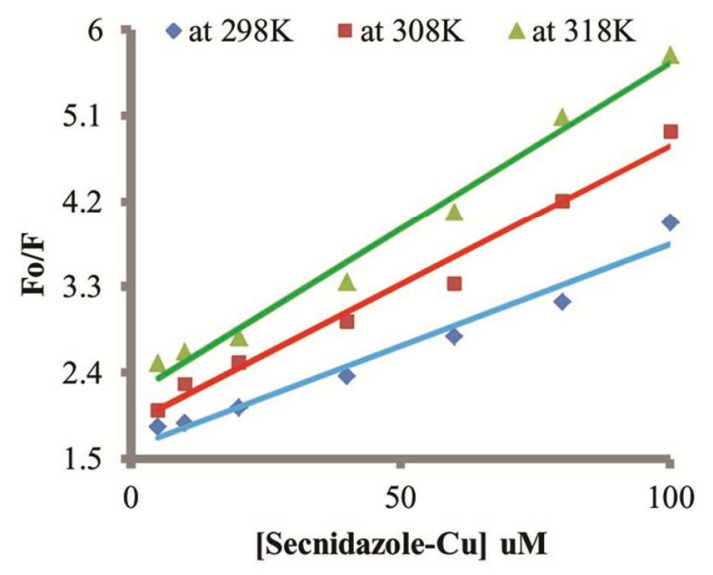

(c)

Figure 2. Stern-Volmer quenching plots of BSA with increasing concentrations of (a) secnidazole (b) secnidazole-Fe complex \& (c) secnidazole-Cu complex at 298K, 308K and 318K.

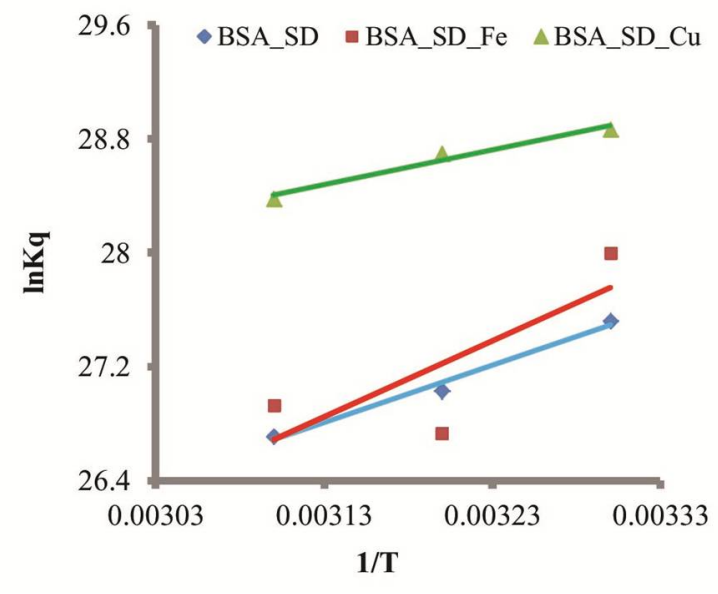

Figure 3. Arrhenius plot for the interaction of BSA with secnidazole, secnidazole-Fe \& secnidazole-Cu complex to determine the activation energy of the quenching process at $\mathrm{pH}$ 7.4.

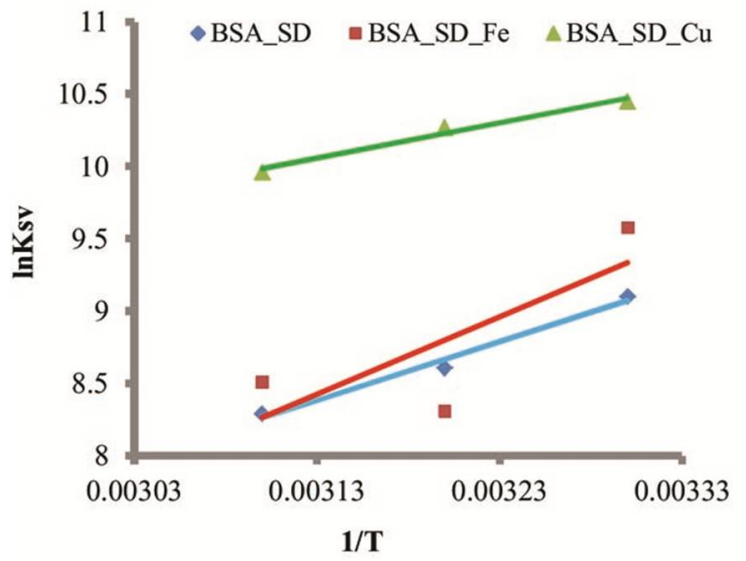

Figure 4. The Van't Hoff Plot for secnidazole, secnidazole-Fe and secnidazole-Cu complex with BSA system at $\mathrm{pH}$ 7.4. 
Table 3. $\log (\mathrm{Fo}-\mathrm{F}) / \mathrm{F}$ values of BSA-secnidazole system at three different temperatures.

\begin{tabular}{ccccc}
\hline $\begin{array}{c}\text { [Quencher] } \\
\text { [Q] uM }\end{array}$ & Log[Q] & \multicolumn{3}{c}{$\log (\mathrm{Fo}-\mathrm{F}) / \mathrm{F}$ values of BSA-SD system } \\
\cline { 3 - 5 } & & at $298 \mathrm{~K}$ & at $308 \mathrm{~K}$ & at 318K \\
\hline 5 & -5.30 & -0.59001 & -0.70116 & -0.81275 \\
10 & -5.00 & -0.45845 & -0.61623 & -0.40334 \\
20 & -4.69 & -0.30938 & -0.30024 & -0.68657 \\
40 & -4.39 & -0.26124 & -0.26431 & -0.44478 \\
60 & -4.22 & -0.17759 & -0.20700 & -0.33526 \\
80 & -4.09 & -0.06863 & -0.15896 & -0.31261 \\
100 & -4.00 & 0.18234 & -0.11569 & -0.19967 \\
\hline
\end{tabular}

Table 4. $\log (\mathrm{Fo}-\mathrm{F}) / \mathrm{F}$ values of BSA-secnidazole-Fe complex system at three different temperatures.

\begin{tabular}{ccccc}
\hline $\begin{array}{c}\text { [Quencher] } \\
\text { [Q] uM }\end{array}$ & $\log [\mathrm{Q}]$ & \multicolumn{2}{c}{$\log (\mathrm{Fo}-\mathrm{F}) / \mathrm{F}$ values of BSA-SD-Fe complex system } \\
\cline { 3 - 5 } & -5.30 & at $298 \mathrm{~K}$ & at 308K & at 318K \\
\hline 5 & -5.00 & -0.81187 & -0.72542 & -0.72168 \\
10 & -4.69 & -0.60885 & -0.51084 & -0.60206 \\
20 & -4.39 & -0.39316 & -0.38939 & -0.53220 \\
40 & -4.22 & -0.25348 & -0.24576 & -0.45864 \\
60 & -4.09 & 0.16860 & -0.23312 & -0.31989 \\
80 & -4.00 & 0.19464 & -0.23312 & -0.22661 \\
100 & & & -0.20360 & -0.17185 \\
\hline
\end{tabular}

Table 5. $\log (\mathrm{Fo}-\mathrm{F}) / \mathrm{F}$ values of BSA-secnidazole-Cu complex system at three different temperatures.

\begin{tabular}{|c|c|c|c|c|}
\hline \multirow{2}{*}{$\begin{array}{c}\text { [Quencher] } \\
\text { [Q] uM }\end{array}$} & \multirow{2}{*}{$\log [\mathrm{Q}]$} & \multicolumn{3}{|c|}{$\log (\mathrm{Fo}-\mathrm{F}) / \mathrm{F}$ values of BSA-SD-Cu complex system } \\
\hline & & at $298 \mathrm{~K}$ & at $308 \mathrm{~K}$ & at $318 \mathrm{~K}$ \\
\hline 5 & -5.30 & -0.07894 & 0.00364 & 0.17697 \\
\hline 10 & -5.00 & -0.05736 & 0.10797 & 0.20974 \\
\hline 20 & -4.69 & 0.01490 & 0.17805 & 0.24847 \\
\hline 40 & -4.39 & 0.13525 & 0.28727 & 0.37063 \\
\hline 60 & -4.22 & 0.25189 & 0.36864 & 0.49009 \\
\hline 80 & -4.09 & 0.33019 & 0.50670 & 0.61131 \\
\hline 100 & -4.00 & 0.47416 & 0.59545 & 0.67536 \\
\hline
\end{tabular}

Table 6. Binding constant $\left(K_{b}\right)$ and number of binding sites (n) of secnidazole-BSA, secnidazole-Fe-BSA and secnidazole-Cu-BSA system at 298K, 308K and 318K.

\begin{tabular}{ccccc}
\hline System & $\mathrm{pH}$ & $\mathrm{T}(\mathrm{K})$ & $\mathrm{K}_{\mathrm{b}}(\mathrm{L} / \mathrm{mol})$ & $\mathrm{n}$ \\
\hline \multirow{2}{*}{ SD - BSA } & \multirow{2}{*}{7.4} & 298 & 93.95 & 0.489 \\
& & 308 & 53.30 & 0.456 \\
& \multirow{2}{*}{7.4} & 318 & 16.05 & 0.367 \\
\hline \multirow{2}{*}{ SD-Fe - BSA } & & 298 & 1143 & 0.736 \\
& \multirow{3}{*}{7.4} & 308 & 24.10 & 0.385 \\
SD - Cu-BSA & & 298 & 25.01 & 0.404 \\
\hline & & 308 & 135.98 & 0.383 \\
& & 318 & 161.77 & 0.423 \\
\hline
\end{tabular}




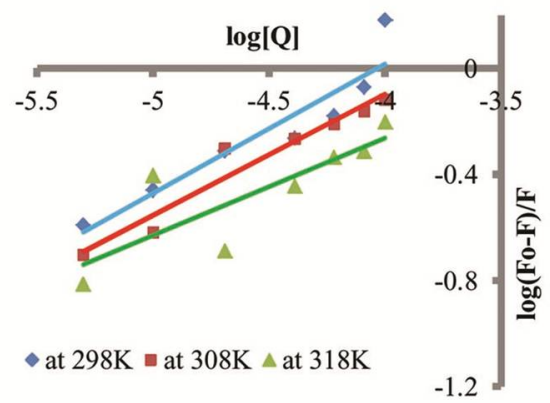

(a)

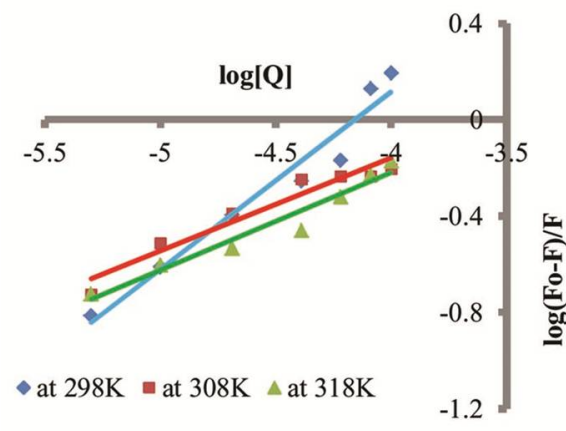

(b)

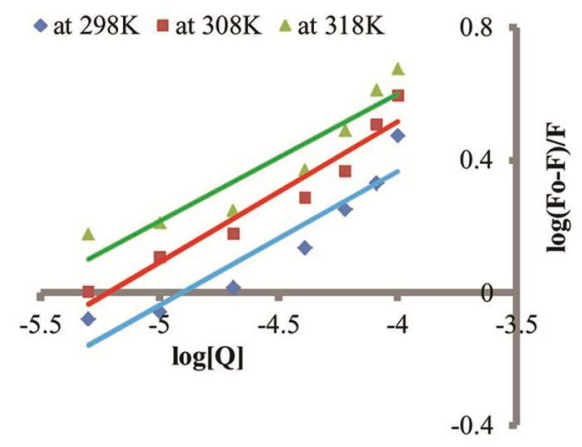

(c)

Figure 5. Double-log plot for binding constant and binding points for (a) BSA-secnidazole, (b) BSA-Secnidazole-Fe complex and (c) BSA-secnidazole-Cu complex system at 298K, 308K and 318K temperatures.

binding constants decreased with the increase in temperature (except BSA-SD-Fe complex system), but the $n$ values remained almost constant and were found to be approximately one that indicated mol ratio of these systems was $1: 1$. That means $1 \mathrm{~mol}$ of drug or drug-metal complex bound with one mol of BSA.

\section{Conclusion}

The interactions mechanism of secnidazole and its iron (II), copper (II) complexes with BSA were investigated by fluorescence quenching method. The experimental results indicated that quenching of the fluorescence of BSA by the drug and the both complexes were probably a static and the reaction was exothermic. The binding parameters which indicated the interaction was a spontaneous process and was driven by enthalpy, and the van der Waals interactions and hydrogen bonding played vital role in the reactions. The binding constants and the number of binding sites were also computed that indicated the drug or its metal complexes bound with BSA at 1:1 ratio.

\section{Acknowledgements}

The authors would like to acknowledge ACI Pharmaceuticals Ltd. for the gift sample of secnidazole. The authors also acknowledge the Centre for Advanced Research in Sciences (CARS) and Department of Pharmaceutical of Chemistry, University of Dhaka, Bangladesh for logistic support. The authors are also thankful to Rajia Sultana and Kanik Kumar Sarker for supporting in the lab work.

\section{References}

Abdel hameed, A. S. 2015. Insight into the interaction between the HIV-1 integrase inhibitor elvitegravir and bovine serum albumin: A spectroscopic study. $J$. Spectrosc. 1, 1-9

Aleksić, M. M. and Kapetanović, V. 2014. An overview of the optical and electrochemical methods for detection of DNA - Drug interactions. Acta. Chim. Slov. 61, 555-573. 
Amin, T. U., Islam, R., Sultan, Z., Sultana, S., Islam, S. and Hasnat, A. 2016. Study of interaction of dextromethorphan hydrobromide with deoxyribonucleic acid by fluorescence quenching. Bangladesh Pharm. J. 19, 197-205.

Ang, C. W., Ang, Z. W. and Hao, J. Z. 2006. Study of the interaction of carbamazepine with bovine serum albumin by fluorescence quenching method. Anal. Sci. 22, 435-438.

Sultana, S., Sayeed, M.S., Ahmed, M.U., Islam, M.S., Bahar, A., Sultam, M.Z. and Hasnat, A. 2013. Interaction of nalbuphine hydrochloride with deoxyribonucleic acid measured by fluorescence quenching. Drug. Res. 63, 224-227.

Cheng, Z., Liu, R. and Jiang, X. 2013. Spectroscopic studies on the interaction between tetrandrine and two serum albumins by chemometrics methods. Spectrochim. Acta A. 115, 92-105.

Joly, R. A., Islam, R., Sultana, S., Rahman, A., Sultan, Z., Islam, M. S., ... Hasnat, A. 2016. Interaction of duloxetine hydrochloride with deoxyribonucleic acid measured by fluorescence spectroscopy. Dhaka Univ. J. Pharm. Sci. 14, 199-206.

Khan, R. H., Rahman, A., Sultan, Z. and Sultan, Z. 2016. Fluorescence spectroscopic studies of in vitro interactions of famotidine and tapentadol hydrochloride with bovine serum albumin. Dhaka Univ. J. Pharm. Sci. 15, 21-26.

Oliveira, A.P.A., Ferreira, J.F.G., Farias, L.M., Magalhães P.P., Teixeira L.R. and Beraldo, H. 2019. Antimicrobial effects of silver (I) and bismuth (III) complexes with secnidazole-derived Schiff base ligands: the role of the nitro group reduction. J. Braz. Chem. S. 11, 2299-2307.

Qiong, W. U., Chaohong, L. I., Yanjun, H. U. and Yi, L. I. U. 2009. Study of caffeine binding to human serum albumin using optical spectroscopic methods. Sci. China, Ser. B: Chem. 52, 2205-2212.

Ran, D., Wu, X., Zheng, J., Yang, J., Zhou, H., Zhang, M. and Tang, Y. 2007. Study on the interaction between florasulam and bovine serum albumin. J. Fluoresc. 17, 721-726.

Refat, M. S., Gehad G. Mohamed. and Mohamed Y., Elsayed. 2013. Spectroscopic and thermal degradation behavior of $\mathrm{Mg}$ ( II ), Ca ( II ), Ba ( II ) and $\mathrm{Sr}$ ( II ) complexes with paracetamol drug. Arab. J. Chem. 10, $1-12$.
Reshma, Vaishanav, S. K., Yadav, T., Sinha, S., Tiwari, S., Satnami, M. L. and Ghosh, K. K. 2019. Antidepressant drug-protein interactions studied by spectroscopic methods based on fluorescent carbon quantum dots. Heliyon. 5, 16-31.

Saha, S., Begum, R., Rahman, A., Sultan, Z., Amran, S. and Hossain, A. 2013. Evaluation of in vitro interaction of metformin with ibuprofen in aqueous medium. Bangladesh Pharm. J. 16, 189-194.

Saha, S., Begum, R., Sultan, Z. and Amjad, F. 2012. In vitro interaction of metformin with diclofenac in aqueous medium. Dhaka Univ. J. Pharm. Sci. 11, 2-7.

Shahabadi, N. and Hadidi, S. 2014. Molecular modeling and spectroscopic studies on the interaction of the chiral drug venlafaxine hydrochloride with bovine serum albumin. Spectrochim. Acta A. 122, 100-106.

Sun, S., Zhou, B., Hou, H., Liu, Y. and Xiang, G. 2006. Studies on the interaction between Oxaprozin-E and bovine serum albumin by spectroscopic methods. Int. J. Biol. Macromol. 39, 197-200.

Suryawanshi, V. D., Walekar, L. S., Gore, A. H., Anbhule, P. V. and Kolekar, G. B. 2016. Spectroscopic analysis on the binding interaction of biologically active pyrimidine derivative with bovine serum albumin. $J$. Pharm. Anal. 6, 56-63.

Tang, H., Shi, Z. H., Li, N. G., Tang, Y. P., Shi, Q. P., Dong, Z. X., ... Duan, J. A. 2015. Investigation on the interactions of scutellarin and scutellarein with bovine serum albumin using spectroscopic and molecular docking techniques. Pharm. Res. 38, 1789-1801.

Tanwir, A., Jahan, R., Quadir, M. A., Kaisar, M. A., and Hossain, K. 2012. Spectroscopic studies of the interaction between metformin hydrochloride and bovine serum albumin. Dhaka Univ. J. Pharm. Sci. 11, 45-49.

Wang, H., Shi, H., Pang, J., Song, X., Xu, C., and Sun, Z. 2016. Studies on the interaction Between triptolide and bovine serum albumin (BSA) by spectroscopic and molecular modeling methods. Afr. J. Tradit. Complement. Altern. Med. 13, 121-129. 